\title{
RELAÇÃo DE Zn, Fe, Cu e Mn ENTRE SOLO E PROGÊNIES DE ERVA-MATE
}

\author{
Josiane Cava Guimarães ${ }^{1 *}$, Carlos Bruno Reissmann ${ }^{1}$, Antonio Carlos Vargas Motta ${ }^{1}$, Sérgio Gaiad ${ }^{2}$, Edilson Batista \\ de Oliveira² ${ }^{2}$ José Alfredo Sturion ${ }^{2}$
}

*Autor para correspondência: josicava@gmail.com

RESUMO: A erva-mate (Ilex Paraguariensis St. Hil.) possui crescimento considerável em solos ácidos e de baixa fertilidade. O conhecimento da relação entre solo e planta contribuirá com os programas de melhoramento genético ao serem selecionadas progênies hábeis na aquisição e assimilação de nutrientes. Neste trabalho objetivou-se avaliar a interferência da procedência e ou progênie nas relações estabelecidas entre os teores de $\mathrm{Zn}, \mathrm{Fe}, \mathrm{Cu}$ e $\mathrm{Mn}$ extraíveis do solo, obtidos pelas soluções extratoras Mehlich-1, na proporção 1:10, e EDTA a 1\%, com os teores nas folhas de erva-mate. No experimento, foram utilizadas, como tratamento, as procedências de erva-mate, Ivaí - PR e Barão de Cotegipe - RS, com cinco progênies cada. As amostras estiveram distribuídas em 4 blocos ao acaso, totalizando 120 amostras de plantas relacionadas a 120 amostras de Latossolo Vermelho Distrófico. Os resultados foram analisados e ajustados em equações de regressão. Na procedência Ivaí foram evidenciadas correlações entre Zn e Mn do solo, com os teores nas folhas, para a progênie 04 , em ambas as soluções extratoras. O Mn do solo se correlacionou com o Mn nas folhas, pelo EDTA, para as progênies 08 e 10, e pelo Mehlich-1, apenas para a progênie 10. Na procedência de Barão de Cotegipe as correlações ocorreram entre $\mathrm{Zn}, \mathrm{Fe}$ e $\mathrm{Cu}$ do solo com os teores nas folhas, pelo EDTA, para as progênies 61, 65 e 69, respectivamente. Houve correlação para $\mathrm{Mn}$ e $\mathrm{Cu}$, pelo Mehlich-1, para as progênies 53 e 69, respectivamente, e para $\mathrm{Cu}$, pelo EDTA, para a progênie 53 .

Palavras-chave: procedências, progênies, melhoramento genético.

\section{RELATION OF Zn, Fe, Cu AND Mn BETWEEN PROGENIES OF MATE-TREE AND SOIL}

\begin{abstract}
The mate tea tree (Ilex Paraguariensis St. Hil.) has considerable growth in acid a low fertility soils. The knowledge of soil and plant relation will contribute to genetic improvement programs, as highly capable progenies in nutrient acquisition may be selected. The objective of this study was to evaluate the interference of provenance and, or progenies, in relations established among the extractable contents of $\mathrm{Zn}, \mathrm{Fe}, \mathrm{Cu}$ and $\mathrm{Mn}$, via Mehlich-1 (1:10); and EDTA (1\%), with the corresponding contents in the mate tea tree leaves. In the experiment two provenances, Ivai-PR and Barão de Cotegipe- $R S$, with five progenies each considered as treatments. The samples were distributed in four randomized blocks, totalizing 120 plant leaf samples, related to 120 soil samples of a Red Distrophic Latosol. The results were analyzed and fitted in regression equations. In Ivai provenance Zn and Mn from the soil correlated with their contents in the leaves for progeny 04, for both extracts. For provenances 08 and 10, soil Mn via EDTA correlated with leaf Mn contents, while via Mehlich-1 only for progeny 10. In the provenance of Barão de Cotegipe, the correlations between soil and leaves for $\mathrm{Zn}, \mathrm{Fe}$ and Cu occurred for the EDTA extract in the progenies 61, 65 and 69 respectively. For Mn and $\mathrm{Cu}$, via Melich-1 the correlations occurred for progenies 53 and 69 respectively, and still for Cu, via EDTA, for progeny 53.
\end{abstract}

Keywords: provenances, progenies, genetic improvement.

\section{INTRODUÇÃO}

As plantas absorvem elementos minerais, por meio das raízes, em formas químicas específicas. Estes podem estar disponíveis no solo como íons livres, ou adsorvidos em superfícies minerais ou orgânicas, como compostos em solução ou precipitados, em estruturas em rede ou na biota do solo. As propriedades que determinam essa disponibilidade são: potencial hidrogeniônico $(\mathrm{pH})$, condições de oxirredução, capacidade de troca de cátions, estrutura, microorganismos, matéria orgânica e conteúdo de água (FROSSARD et al., 2000). Há de se considerar, imprescindivelmente, os fatores genéticos da planta como sendo responsáveis pela absorção de minerais, além das condições ambientais e da influência das variáveis agronômicas (JACQUES et al., 2007). O conhecimento das características e exigências nutricionais da cultura de ervamate permitirá compreender e selecionar indivíduos que apresentem aptidões na utilização de nutrientes, apontando as melhores plantas dentro das melhores progênies. Para Guimarães (1993), as diferenças quanto à absorção de nutrientes e o desenvolvimento se manifestam entre espécies, procedências, progênies e clones de espécies florestais, onde os genótipos que crescem bem em solos de baixa fertilidade devem ser selecionados. Sturion et al. (2004) trabalhando com dezesseis progênies de Ilex

1 Universidade Federal do Paraná - Curitiba, Paraná, Brasil

2 Embrapa Florestas - Colombo, Paraná, Brasil

Cerne, Lavras, v. 20, n. 2, p. 285-292, abr./jun. 2014 
paraguariensis St. Hil cultivadas em três classes de solo verificaram que os teores de polifenóis totais, taninos e cafeína podem ser melhorados pela seleção de progênies, onde o ganho genético para cafeína poderia ser feito para determinada região, e ser realizado localmente, para taninos e polifenóis totais. Em pesquisa realizada por Nakamura et al. (2009) foram evidenciadas diferenças entre oito progênies de erva-mate nos níveis de saponinas triterpênicas, cafeína, teobromina, ácido clorogênico e atividade antioxidante, confirmando que o fator genético é importante na variabilidade de compostos fitoquímicos. Os seres humanos adquirem elementos químicos necessários ao seu metabolismo, por meio da alimentação, provenientes de culturas tratadas, ou não, com fertilizantes minerais. Torna-se indispensável o conhecimento de variedades com maior capacidade na aquisição e translocação de nutrientes, principalmente metais que exercem funções importantes na fisiologia humana, animal e vegetal, interagindo com as biomoléculas (BENITE et al., 2007). Neste trabalho, objetivou-se avaliar a interferência da procedência e ou progênie na correlação entre os teores foliares totais de $\mathrm{Zn}$, $\mathrm{Fe}, \mathrm{Cu}$ e Mn em duas procedências de erva-mate, Ivaí - PR e Barão de Cotegipe - RS, e suas respectivas progênies, e relacioná-los aos teores extraíveis do solo, obtidos por Mehlich-1 e EDTA, em Latossolo Vermelho Distrófico, sem adubação e calagem.

\section{MATERIAL E MÉTODOS}

A área experimental localiza-se no município de Ivaí - PR na Fazenda Vila Nova da Ervateira Bitumirim e faz parte do PROMEGEM - Programa de Melhoramento Genético da Embrapa. Considerou-se para o tratamento as procedências Ivaí - PR e Barão de Cotegipe - RS com 5 progênies cada (Tabela 1), distribuídas em 4 blocos ao acaso, com 3 plantas matrizes, totalizando 120 amostras. Foram coletados ramos maduros da cultura, relativos ao último período de crescimento, dispensando as brotações dos meristemas terminais. Após a secagem dos ramos, em estufa, até peso constante, foram retiradas 100 folhas para o processamento das amostras. A coleta foi realizada no período de inverno (julho de 2008), segundo Reissmann et al. (1983) na porção mediana da copa viva em exposição norte, com máxima luminosidade (JONES; CASE, 1990; ZÖTTL, 1973). As amostras de solo foram compostas por três amostras simples coletadas à profundidade de $0 \mathrm{a} 20 \mathrm{~cm}$, na projeção da periferia da copa de cada planta, totalizando também 120 amostras. Em decorrência da superficialidade das raízes de erva-mate esta profundidade tem sido adotada nos trabalhos com a cultura (REISSMANN et al., 2003; ROBASSA, 2005). Nos casos em que o coeficiente de Pearson (r) foi significativo, os resultados foram ajustados em equações de regressão, com auxílio do programa Excel, tendo como variável dependente o teor do micronutriente nas folhas relacionado ao disponível no solo. O coeficiente de determinação (R2) foi considerado quando $\geq$ a 0,55 (STEEL; TORRIE, 1960). As análises químicas dos teores foliares totais dos micronutrientes $\mathrm{Zn}, \mathrm{Fe}, \mathrm{Cu}$ e $\mathrm{Mn}$ foram realizadas após incineração em mufla a $500^{\circ} \mathrm{C}$ (HILDEBRAND et al., 1977; JONES; CASE, 1990) e solubilização em $\mathrm{HCl} 3 \mathrm{~mol}$ L-1 (MARTINS; REISSMANN, 2007). Os micronutrientes no solo foram extraídos por Mehlich-1 (1:10) com agitação por 10 minutos, deixados em repouso por 16 horas, conforme Empresa Brasileira de Pesquisa Agropecuária - EMBRAPA (1997) e por meio de solução aquosa de $\mathrm{Na}_{2}$ EDTA. $2 \mathrm{H}_{2} \mathrm{O}$ a $1 \%$, com agitação por 120 minutos em agitador circular horizontal, seguido de repouso por uma noite, adaptado de Brown et al. (1971). As leituras foram realizadas por espectrofotometria de absorção atômica.

Tabela1 - Procedências e respectivas progênies de erva-mate (Ilex paraguariensis St. Hil.) utilizadas no experimento.

Table 1 - Provenances with respective progenies of mate-tea tree (Ilex paraguariensis St. Hil.) used in the experiment.

\begin{tabular}{llllll}
\hline \multicolumn{1}{c}{ Procedências } & \multicolumn{5}{c}{ Progênies } \\
\hline Ivaí- PR & 04 & 08 & 10 & 11 & 15 \\
Barão de Cotegipe - RS & 53 & 59 & 61 & 65 & 69 \\
\hline
\end{tabular}

\section{RESULTADOS E DISCUSSÃO}

Os resultados foram inicialmente submetidos a matrizes de correlação. Após, evidenciou-se que as regressões polinomiais entre os valores disponíveis dos micronutrientes no solo, obtidos pelas soluções Mehlich-1 e EDTA, foram as que melhor descreveram a relação com as quantidades determinadas nas folhas da erva-mate. As correlações entre os micronutrientes do solo e das folhas foram marcantes em relação ao tipo de extrator e às progênies dentro das procedências.

Na procedência de Ivaí - PR houve relação entre a concentração dos nutrientes foliares de $\mathrm{Mn}$ e $\mathrm{Zn}$ na progênie 04 , com valores extraídos do solo, pelas soluções Mehlich-1 $\left(\mathrm{R}^{2}=0,62\right)($ Figura $1-\mathrm{A})$ e EDTA $\left(\mathrm{R}^{2}=0,85\right)$ (Figura $1-\mathrm{B})$ e pelos extratores Mehlich-1 $\left(\mathrm{R}^{2}=0,61\right)$ (Figura $2-\mathrm{A}$ ) e EDTA $\left(\mathrm{R}^{2}=0,58\right)$ (Figura $2-\mathrm{B}$ ). Na progênie $10 \mathrm{o}$ Mn foliar correlacionou-se com Mn extraído do solo pelo Mehlich-1 $\left(\mathrm{R}^{2}=0,76\right)$ (Figura $\left.3-\mathrm{A}\right)$ e EDTA $\left(\mathrm{R}^{2}=0,71\right)$ (Figura $\left.3-\mathrm{B}\right)$. E na progênie $08 \mathrm{o}$ Mn foliar se correlacionou com valores extraídos do solo apenas pelo $\operatorname{EDTA}\left(\mathrm{R}^{2}=0,58\right)$. 

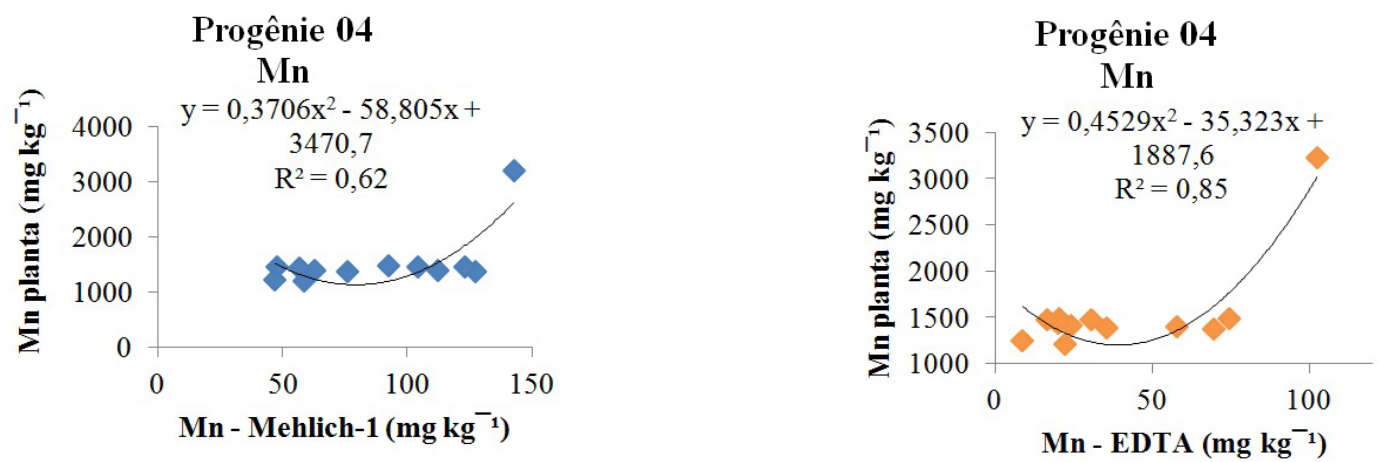

Figura 1 - Relações obtidas para a progênie 04 de Ivaí, entre manganês na planta e no solo, extraídos pelo Mehlich-1 e EDTA.

Figure 1 - Relations obtained for progeny 04 of Ivaí provenance, between plant and soil manganese, extracted by Mehlich-1 e EDTA.
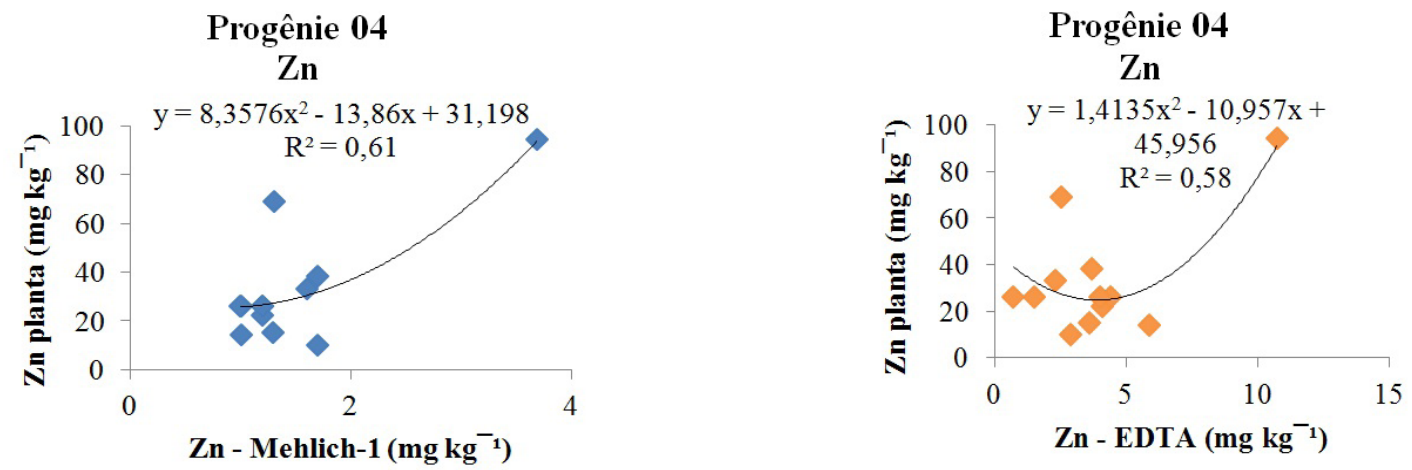

Figura 2 - Relações obtidas para a progênie 04 de Ivaí, entre zinco na planta e no solo, extraídos pelo Mehlich-1 e EDTA.

Figure 2 - Rations obtained for 04 progeny of Ivaí, between plant and soil zinc, extracted by Mehlich-1 and EDTA.
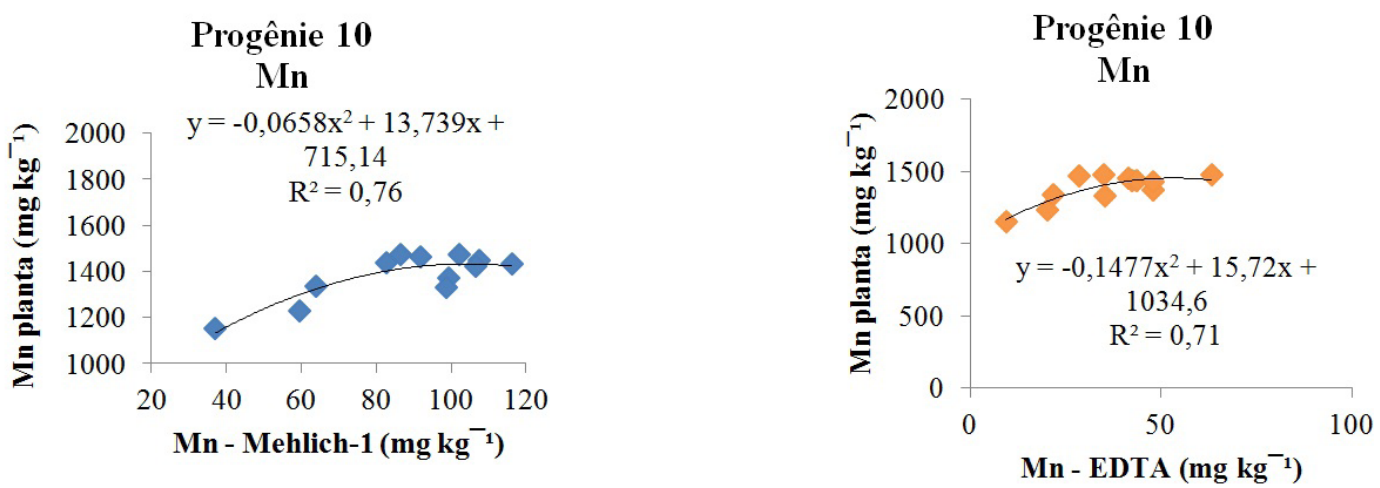

Figura 3 - Relações obtidas para a progênie 10 de Ivaí, entre manganês na planta e no solo, extraidos pelo Mehlıch-1 e ED iłA.

Figure 3 - Rations obtained for progeny04 of Ivaí provenance, between plant and soil manganese, extracted by Mehlich-1 and EDTA.

Cerne, Lavras, v. 20, n. 2, p. 285-292, abr./jun. 2014 
O valor médio encontrado, nesta pesquisa, para a relação $\mathrm{Ca}: \mathrm{Mg}$ foi de 3:1 para progênies de Ivaí e Barão de Cotegipe. Em trabalhos recentes, consideramse relações no solo Ca:Mg entre 4:1 e 8:1 como sendo adequadas, mas, conforme relatado por Holzschuh (2007), há controvérsias, pois a maioria dos experimentos ocorrem em fase inicial de crescimento das plantas, com pequena área de amostragem, em diferentes condições. Ainda segundo o autor, a relevância da relação $\mathrm{Ca}: \mathrm{Mg}$ pode não estar necessariamente ligada ao fornecimento dos cátions pelo solo, mas com a capacidade nutricional diferenciada das espécies. Para a progênie 04 de Ivaí verificou-se que os valores do quociente $\mathrm{Ca}: \mathrm{Mg}$ no solo, extraídos por $\mathrm{KCl} 1 \mathrm{~mol} \mathrm{~L}{ }^{-1}$, relacionaram-se com a concentração e conteúdo foliar de Zn, conforme observado nas Figuras 4A e $4 \mathrm{~B}$, respectivamente. A relação $\mathrm{Ca}: \mathrm{Mg}$ possivelmente interferiu nos valores de $\mathrm{Zn}$ obtidos com a solução extratora Mehlich-1 de comprovada característica ácida. Para Nelson et al. (1959) as soluções extratoras ácidas podem reagir com carbonatos e bicarbonatos livres no solo. Sendo assim, essas reações podem ter favorecido a extratibilidade de $\mathrm{Zn}$ em solo ácido, como foi o caso desta pesquisa. Por outro lado, Moreira et al. (2003) verificando a ação do Mg na absorção de Mn e Zn, separadamente, em raízes de quatro cultivares de soja, concluíram que o $\mathrm{Mg}$, nas três doses aplicadas, não interferiu na absorção de Mn e Zn, considerando a inibição do Mg não competitiva, sendo os cultivares responsáveis pelas diferenças.
A

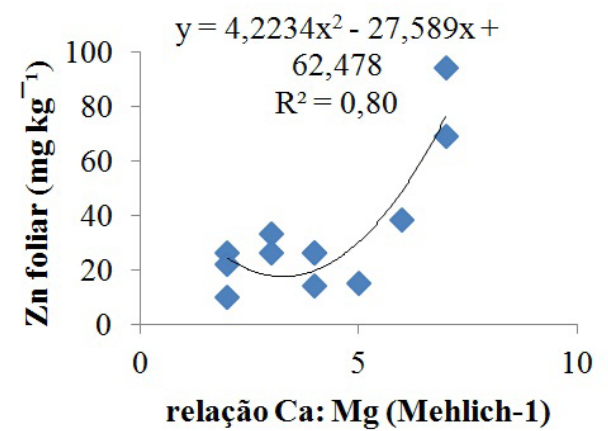

B

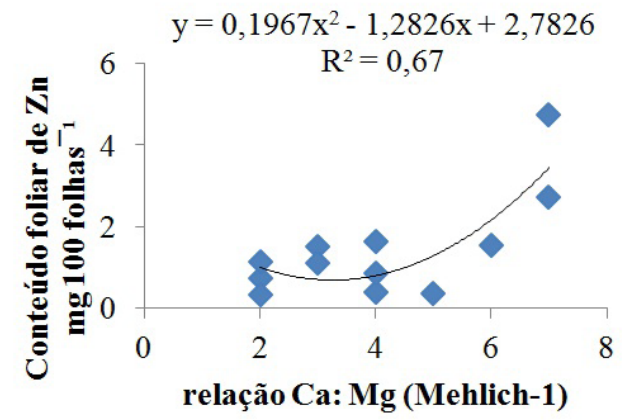

Figura 4 - Variação do teor foliar e conteúdo foliar de Zn na progênie 04 procedente de Ivaí, em função da relação Ca:Mg no solo.

Figure 4 - Variation in leaves concentration and leaves content $\mathrm{Zn}$ in the 04 progeny of Ivai provenance, in function relation Ca:Mg in soil.

Na procedência de Barão de Cotegipe - RS, os ajustes de regressão entre concentração foliar de $\mathrm{Zn}, \mathrm{Fe}$, $\mathrm{Cu}$ e $\mathrm{Mn}$ das diferentes progênies com seus respectivos valores extraídos do solo, pelos dois métodos utilizados, constatou que houve correlação para $\mathrm{Mn}$ apenas para Mehlich-1 $\left(\mathrm{R}^{2}=0,57\right)$ na progênie 53 , enquanto $\mathrm{Zn}$ e Fe se correlacionaram apenas por EDTA $\left(\mathrm{R}^{2}=0,66\right)$ na progênie 61 e Fe na progênie $65\left(\mathrm{R}^{2}=0,57\right)$. O Cu se correlacionou pelo Mehlich-1 $\left(\mathrm{R}^{2}=0,55\right)$ e EDTA $\left(\mathrm{R}^{2}=\right.$ $0,69)$ para a progênie 69 , sendo positiva para Mehlich-1 (Figura 5A) e negativa para EDTA (Figura 5B) com distribuição dos pontos na curva ocorridos de forma distinta. O solo utilizado neste trabalho possui teor de argila superior a $60 \%$, sendo classificado como muito argiloso e teor médio de carbono entre 30,0 e $31,4 \mathrm{~g}$ $\mathrm{dm}^{-3}$ para as procedências Barão de Cotegipe e Ivaí, respectivamente. Para a progênie 04 de Ivaí observou-se que os valores de $\mathrm{Cu}$ por Mehlich-1, foram influenciados pelo teor de carbono, diminuindo com o seu aumento (Figura 6), pois para McBride (1994) o Cu é entre os metais de transição o que sofre maior complexação pela matéria orgânica do solo.

Cerne, Lavras, v. 20, n. 2, p. 285-292, abr./jun. 2014 

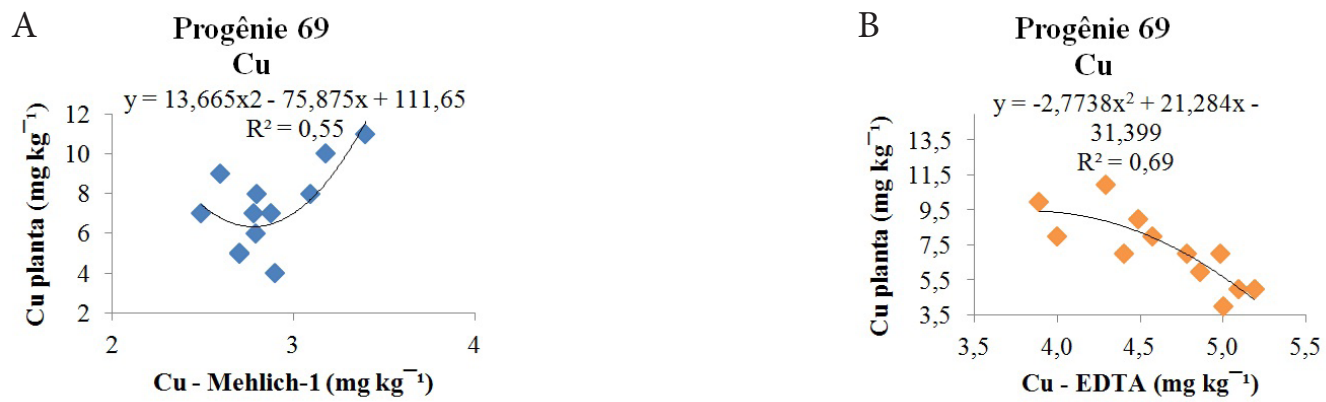

Figura 5 - Relações obtidas para a progênie 69 de Barão de Cotegipe, entre coure nıa pranıla e nı soıu, exıraıuo peıu ıMehlich-1 e EDTA.

Figure 5 - Relations obtained for progeny 69 of Barão de Cotegipe provenance, between plant and soil manganese, extracted by Mehlich-1 e EDTA.

Progênie 04

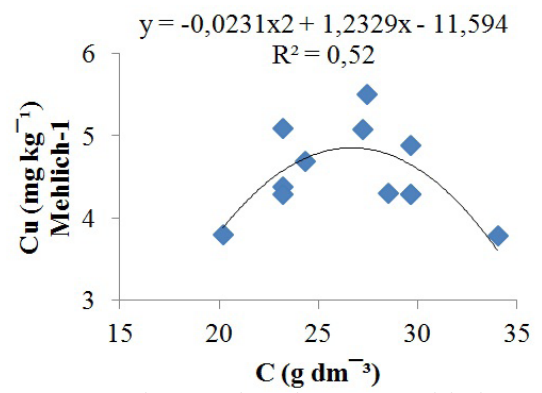

Figura 6 - Variação do teor de cobre por Mehlich-1 na progênie 04 em função do teor de carbono no solo.

Figure 6 - Variation of copper content by Mehlich-1 in the 04 progeny as a function of carbon content in soil.

Para a escolha de um método de análise de solo, faz-se necessário que ocorra relação positiva entre a disponibilidade do elemento no solo e a quantidade contida do nutriente na parte representativa da planta (BORTOLON; GIANELLO, 2009). Esse pressuposto, no entanto, para EDTA, conforme relatado, não ocorreu com a progênie 69. Esse fato, pode ser explicado nesta progênie com a relação pH SMP e teor de Cu por EDTA (Figura 7) onde o aumento do $\mathrm{pH}$ diminuiu a disponibilidade de $\mathrm{Cu}$ para a cultura. Em solos ácidos, com o aumento do $\mathrm{pH}$ ocorre maior densidade de carga elétrica nos sítios de adsorção (ALLOWAY, 1990), provocando a dissociação de íons hidrogênio $\left(\mathrm{H}^{+}\right)$dos grupos hidroxilas $\left(\mathrm{OH}^{-}\right)$da matéria orgânica e de óxidos de ferro e alumínio. Sendo assim, o cobre pode ter sido adsorvido, tornando-se indisponível para a planta.

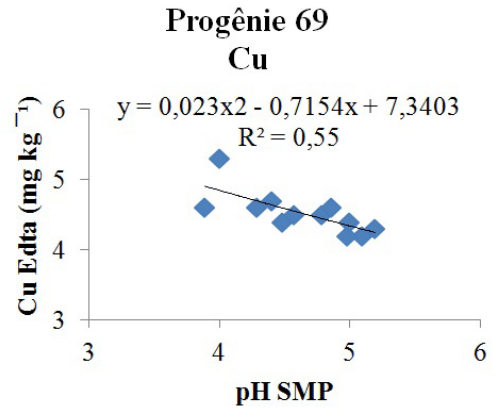

Figura 7 - Variação do teor de cobre na progênie 69 por EDTA em função do $\mathrm{pH}$.

Figure 7 - Variation of copper content in the 69 progeny by EDTA as a function of $\mathrm{pH}$.

Os maiores coeficientes de determinação foram observados para as progênies 04 e 10 de Ivaí, relativas à $\mathrm{Mn}$, pelos dois extratores. No entanto, não podemos afirmar a adequabilidade desses extratores em acessar frações biodisponíveis, uma vez que o comportamento no solo das soluções ácidas e quelantes são parecidos, sendo as correlações entre esses métodos muito próximas (ABREU et al., 2007). Há de se considerar a influência das progênies 04 e 10 de Ivaí nas correlações de $\mathrm{Zn}$ e Mn, e da progênie 69 de Barão de Cotegipe na correlação de $\mathrm{Cu}$, pelos dois extratores, já que o solo foi bastante homogêneo, no âmbito das repetições, e as condições em que se encontravam as demais progênies foram similares. Os extratores não foram igualmente eficientes para correlacionar todos os micronutrientes nas mesmas progênies, supondo que estas interagem de maneira

Cerne, Lavras, v. 20, n. 2, p. 285-292, abr./jun. 2014 
diferenciada com o solo na disponibilidade dos nutrientes interferindo na apresentação das formas químicas destes no solo. Sugere-se que estudos envolvendo micronutrientes devem ser realizados, num contexto mais específico, com maior número dessas progênies, de maneira a definir o extrator adequado que se aproxime da aptidão nutricional da espécie.

\section{CONCLUSÃO}

- Os resultados obtidos indicaram que as procedências (duas) e progênies (cinco) são importantes no estabelecimento das relações das concentrações foliares dos micronutrientes ( $\mathrm{Zn}, \mathrm{Fe}, \mathrm{Cu}$ e $\mathrm{Mn}$ ) com valores disponíveis no solo.

- Os extratores testados, quelato (EDTA 1\%) e ácido (Mehlich-1), não conseguiram simular com eficiência e consistência os teores foliares para diferentes procedências e progênies.

- Os micronutrientes Zn e Mn disponíveis no solo, pelos extratores Mehlich-1 e EDTA, correlacionaram-se com as quantidades nas folhas para a progênie 04 de Ivaí.

- Mn disponível no solo, pelo Mehlich-1 e pelo EDTA, se correlacionou ao Mn das folhas para a progênie 10 de Ivaí.

- O micronutriente $\mathrm{Cu}$ disponível no solo, pelos extratores Mehlich e EDTA, se correlacionou ao $\mathrm{Cu}$ nas folhas para a progênie 69 da procedência Barão de Cotegipe. Essas correlações foram opostas, sendo positiva para Mehlich-1 e negativa para EDTA.

- O quociente $\mathrm{Ca}: \mathrm{Mg}$ do solo se correlacionou com o teor de Zn nas folhas, pelo Mehlich-1, e com o conteúdo foliar, desse micronutriente, para a progênie 04 de Ivaí.

\section{REFERÊNCIAS}

ABREU, C. A.; LOPES, A. S.; SANTOS, G. C. G. Micronutrientes. In: NOVAIS, R. F.; ALVAREZ, V. H.; BARROS, N. F.; FONTES, R. L. F.; CANTARUTTI, R. B.; NEVES, J. C. L. (Ed.). Fertilidade do solo. Viçosa, MG: Sociedade Brasileira de Ciência do Solo, 2007. p. 645-736.

ALLOWAY, B. J. Heavy metals in soil. New York: J. Willey, 1990. $339 \mathrm{p}$.

BENITE, A. M. C.; MACHADO, S. de P.; BARREIRO, E. J. Uma visão da química bioinorgânica medicinal. Química Nova, São Paulo, v. 30, n. 8, p. 2062-2067, 2007.

Cerne, Lavras, v. 20, n. 2, p. 285-292, abr./jun. 2014
BORTOLON, L.; GIANELLO, C. Disponibilidade de cobre e zinco em solos do sul do Brasil. Revista Brasileira de Ciência do Solo, Viçosa, v. 33, p. 647-658, 2009.

BROWN, A. L.; QUICK, J.; EDDINGS, J. L. A comparison of analytical methods for soil zinc. Soil Science Society of America Proceedings, Madison, v. 35, p. 105-107, 1971. EMPRESA BRASILEIRA DE PESQUISA AGROPECUÁRIA. Centro Nacional de Pesquisa de Solos. Manual de métodos de análise de solos. 2. ed. Rio de Janeiro, 1997. 212 p.

FROSSARD, E.; BUCHER, M.; MÄCHLER, F.; MOZAFAR, A.; HURRELL, R. Potential for increasing the content and bioavailability of $\mathrm{Fe}, \mathrm{Zn}$ and $\mathrm{Ca}$ in plants for human nutrition. Journal of the Science of Food and Agriculture, London, v. 80, p. 861-879, 2000.

GUIMARÃES, H. S. Variabilidade genética para eficiência nutricional em progênies de Eucalytus camaldulensis e Eucalyptus citriodora. 1993. 68 p. Dissertação (Mestrado em Ciência Florestal) Universidade Federal de Viçosa, Viçosa, 1993.

HILDEBRAND, C.; HILDEBRAND, E. E.; REISSMANN, C. B. Manual de análise química de solo e planta. Curitiba: UFPR, 1977. 225 p.

HOLZSCHUH, M. J. Eficiência de calcário calcítico e dolomítico na correção da acidez de solos sob plantio direto. 2007. 85 p. Dissertação (Mestrado em Ciência do Solo) - Universidade Federal de Santa Maria, Santa Maria, 2007.

JACQUES, R. A.; ARRUDA, E. J.; OLIVEIRA, L. C. S. de; OLIVEIRA, A. P. de; DARIVA, C.; OLIVEIRA, V. de; CARAMÃO, E. B. Influence of agronomic variables on the macronutrient and micronutrient contents and thermal behavior of mate tea leaves (Ilex paraguariensis). Journal of Agriculture and Food Chemistry, Easton, v. 55, p. 7510-7516, 2007.

JONES JUNIOR, J. B.; CASE, V. W. Sampling handling, and analyzing plant tissue samples. In: WESTERMAN, A. (Ed.). Soil testing and plant analysis. Madison: SSSA, 1990. p. 389-427. (SSSA Book Series, 3).

MARTINS, A. P. L.; REISSMANN, C. B. Material vegetal $\mathrm{e}$ as rotinas laboratoriais nos procedimentos químico-analíticos. Sciencia Agraria, Curitiba, v. 8, n. 1, p. 1-17, 2007. 
MCBRIDE, M. B. Environmental chemistry of soils. New York: Oxford University, 1994. 416 p.

MOREIRA, A.; MALAVOLTA, E.; HEINRICHS, R.; TANAKA, R. T. Influência do magnésio na absorção de manganês e zinco por raízes destacadas de soja. Pesquisa Agropecuária Brasileira, Brasília, v. 38, n. 1, p. 95-101, jan. 2003.

NAKAMURA, K. L.; CARDOZO JUNIOR, E. L.; DONADUZZI, C. M.; SCHUSTER, I. Genetic variation of phytochemical compounds in progenies of Ilex paraguariensis St. Hil. Brazilian Society of Plant Breeding. Crop Breeding and Applied Biotechnology, Londrina, v. 9, p. 116-123, 2009.

NELSON, J. L.; BOAWN, L. C.; VIETS, F. G. A. Method for assessing zinc status of soils using acidextractable zinc and "titratable alkalinity"values. Soil Science, Baltimore, v. 88, p. 275-283, 1959.

REISSMANN, C. B.; DÜNISCH, O.; BOEGER, M. R. T. Beziehungen Zwischen Ernährungsbiologischen (Fe, $\mathrm{Mn}$ und $\mathrm{Ca}$ ) und strukturellen merkmahlen ausgewälter morphotypen der mate-pflanze (Ilex paraguariensis $\mathrm{St}$. Hil.). In: HÜTTEL, R. (Ed.). Boden, wald und wasser. Aachen: Shaker Verlag, 2003. p. 146-171.

REISSMANN, C. B.; ROCHA, H.; KOELHLER, C. W.; CALDAS, R. L.S.; HILDEBRAND, E. E. Bioelementos em folhas e hastes de erva-mate (Ilex paraguariensis $\mathrm{St}$. Hil.) sobre cambissolos na região de Mandirituba, PR.

Revista Floresta, Curitiba, v. 14, n. 2, p. 49-54, 1983.

ROBASSA, J. C. Caracterização química de três morfotipos de erva-mate (Ilex paraguariensis $\mathrm{St}$. Hil.) em Latossolo Vermelho escuro álico na região de Ivaí, PR. 2005. 55 p. Dissertação (Mestrado em Ciência do Solo) - Universidade Federal do Paraná, Curitiba, 2005.

STEEL, R. G. D.; TORRIE, J. H. Principles and procedures of statistics. New York: McGraw-Hill, 1960. $481 \mathrm{p}$.

STURION, J. A.; CORREA, G.; RESENDE, M. D. V. de; CARDOSO JUNIOR, E. L.; DONADUZZI, C. M. Controle genético dos teores de polifenóis totais, taninos e cafeína em progênies de erva-mate (Ilex paraguariensis St.Hil.) cultivadas em três classes de solos. Colombo: EMBRAPA Florestas, 2004. 16 p.

(Boletim de Pesquisa e Desenvolvimento, 16).
ZÖTTL, H. W. International symposium on forest fertilization. Freiburg: University of Freiburg, 1973.

Recebido: 13 de fevereiro de 2012; aceito: 05 de setembro de 2013. 
